\title{
Transcutaneous vagus and trigeminal nerve stimulation for neuropsychiatric disorders: a systematic review
}

\author{
Estimulação transcutânea do nervo vago e do nervo trigêmeo para o tratamento de \\ distúrbios neuropsiquiátricos: revisão sistemática
}

Pedro Shiozawa', Mailu Enokibara da Silva', Thais Cristina de Carvalho', Quirino Cordeiro', André R. Brunoni ${ }^{2}$, Felipe Fregni ${ }^{3,4}$

\begin{abstract}
We reviewed trigeminal nerve stimulation (TNS) and transcutaneous vagus nerve stimulation (tVNS). All techniques have shown preliminary promising results, although the results are mixed. Method: We performed a systematic review of the Medline and Embase databases, with no constraint to dates, through June 2013. The keywords were [(1) trigeminal nerve stimulation OR (2) cranial nerve OR (3) trigemin* OR (4) transcutaneous VNS OR (5) transcutaneous cranial nerve stimulation] and (6) mental disorders. Results: We included four preclinical and clinical five studies on TNS. All clinical data were based on open-label studies with small samples, which diminished the external validity of the results, thus reflecting the modest impact of TNS in current clinical practice. Of the tVNS clinical trials, three assessed physiological features in healthy volunteers, and one examined patients with epilepsy. Conclusion: TNS and tVNS improve treatment of particular neuropsychiatric disorders such as depression.
\end{abstract}

Keywords: transcutaneous nerve stimulation, trigeminal stimulation, neuropsychiatric disorders.

\section{RESUMO}

O uso de estimulação de nervos cranianos de maneira transcutânea tem sido uma estratégia em desenvolvimento recente. Diferentes estudos apontam para resultados clínicos favoráveis no tratamento de diferentes quadros neuropsiquiátricos. Método: Revisão sistemática da literatura com base nas bibliotecas eletrônicas Medline e Embase, sem restrição de data inicial, até agosto de 2013. Os termos de busca utilizados foram [(1) trigeminal nerve stimulation OR (2) cranial nerve OR (3) trigemin* OR (4) transcutaneous VNS OR (5) transcutaneous cranial nerve stimulation] and (6) mental disorders. Resultados: Incluímos quatro estudos pré-clinicos e cinco estudos clínicos abordando estimulação do nervo trigêmeo. Todos os estudos foram abertos, com pequenas amostras, o que reduz a validade externa dos dados, refletindo a ainda incipiente atuação da técnica, apesar de promissora. Considerando-se a estimulação do nervo vago, três artigos avaliaram aspectos fisiológicos em voluntários saudáveis e um artigo estudou pacientes com epilepsia. Conclusão: As estratégias de estimulação transcutânea de nervos cranianos, apesar de incipiente, tem demonstrado resultados clínicos favoráveis no tratamento de distúrbios neuropsiquiátricos.

Palavras-chave: estimulação transcutânea de nervos cranianos, estimulação do nervo trigêmeo, distúrbios neuropsiquiátricos.

Different nonpharmacological brain stimulation techniques have been used in clinical neurology and psychiatry, such as electroconvulsive therapy (ECT), repetitive transcranial magnetic stimulation (rTMS), vagus nerve stimulation (VNS), transcranial direct current stimulation (tDCS), deep brain stimulation (DBS), stereotactic surgery and trigeminal nerve stimulation (TNS) $)^{1,2,3,4,5}$. Theoretically, such techniques present different mechanisms of action. For instance, ECT nonspecifically increases brain activity and excitability through controlled, electrically induced seizures; rTMS through an electromagnetic field induces intracortical eletric currents which may madulate neuronal activity focally; and

\footnotetext{
${ }^{1}$ Departamento de Psiquiatria, Faculdade de Ciências Médicas da Santa Casa de São Paulo, Sao Paulo SP, Brazil;

${ }^{2}$ Centro de Pesquisa Clínica, Hospital Universitário, Universidade de São Paulo, Sao Paulo SP, Brazil;

${ }^{3}$ Laboratory of Neuromodulation, Harvard Medical School, Harvard University, United States;

${ }^{4}$ Center of Clinical Research Training, Harvard University, United States.
}

Correspondence: Pedro Shiozawa; Departamento de Psiquiatria, Faculdade de Ciências Médicas da Santa Casa de São Paulo; Rua Major Maragliano, 241 Vila Mariana; 04600-010 São Paulo SP, Brasil; E-mail: pshiozawa@yahoo.com.br

Conflict of interest: The authors declare no conflict of interest.

Received 10 September 2013; Received in final form 26 March 2014; Accepted 15 April 2014. 
tDCS modifies brain excitability through weak, direct electric currents. It is assumed that such techniques are top-down i.e., they indirectly modulate subcortical activity through primary network changes in cortical activity.

Conversely, both trigeminal and vagus nerve stimulation modulate brain activity through bottom-up mechanisms that is, by stimulating cranial nerves whose nuclei lie in the brain stem, which, in turn, make extensive connections to the limbic cortex and monoaminergic nuclei. The vagus nerve, for instance, innervates the nucleus tractus solitarius bilaterally, which is connected to regions of the brain that are associated with the regulation of mood, emotion, and seizure activity ${ }^{6}$.

Similarly, the trigeminal nerve has extensive connections to the brainstem and other brain structures. The trigeminal nerve has 3 major sensory branches over the face, all of which are bilateral. The trigeminal ganglion, located in the Meckel cave (cavum trigeminale), projects to the trigeminal nucleus which makes reciprocal projections to the nucleus tractus solitarius, locus coeruleus, and reticular formation ${ }^{7}$.

The aim of this review was to systematically review all clinical and preclinical studies on both transcutaneous trigeminal (TNS) and vagus (tVNS) nerve stimulation as to understand the therapeutic and mechanistic aspects of these interventional techniques in the treatment of neuropsychiatric disorders. This is important because these techniques might modulate brain structures through transcutaneous electric nerve stimulation, although this has not been systematically assessed yet.

We performed a systematic review following the PRISMA (Preferred Reporting Items for Systematic Reviews and Meta-Analyses) Statement ${ }^{8}$. The methodological details are discussed below.

\section{LITERATURE REVIEW}

We searched the Medline and Embase databases for the keywords: [(1) trigeminal nerve stimulation OR (2) cranial nerve OR (3) trigemin* OR (4) transcutaneous VNS OR (5) transcutaneous cranial nerve stimulation] and (6) mental disorders. These terms were selected even in the absence of specific Mesh terms (items 1, 3, 4 and 5) as to increase sensitivity. The date limits were from the first date available to June 2013. We also looked for potential relevant articles in the study references and contacted experts in the field.

\section{ELIGIBILITY CRITERIA}

We adopted the following inclusion criteria: (a) manuscript written in English, Spanish, or Portuguese; and (b) clinical trials; interventional studies; preclinical studies.
Therefore, other types of articles, such as case reports and editorial letters, studies that assessed conditions other than neuropsychiatric disorders and studies that assessed interventions other than tVNS and TNS were excluded.

\section{DATA EXTRACTION}

The following variables were extracted per a structured checklist that we developed:

(a) Overview - study design, authors, year of publication, technique summary, other relevant data;

(b) Demographics - total sample (number), age (years), gender (percentage females);

(c) Assessment of mental disorder - method of diagnosis (clinical interview, structured checklist); and

(d) Outcomes - description of each study's principal results.

\section{QUALITY ASSESSMENT}

To assess the methodological heterogeneity between studies, each report was evaluated with regard to quality, focusing on 2 critical methodological issues:

(a) Internal validity - for clinical studies, we followed the Cochrane guidelines to determine the risk of bias in randomization/allocation (selection bias), blinding and control comparison (performance bias), and outcome assessment and reporting (attrition, measurement, and reporting biases).

(b) Construct validity - we determined whether the operational criteria for mental disorder, vagus nerve stimulation, and trigeminal nerve stimulation were appropriate - i.e., whether each study fulfilled the following criteria: (i) clinical or preclinical studies that focused on transcutaneous cranial nerve stimulation; (ii) articles on mental disorders.

\section{QUANTITATIVE ANALYSIS}

Anticipating that there would be few studies and that between-study heterogeneity would be important, our initial aim was not to perform a quantitative analysis, such as meta-analysis and meta-regression. Instead, we reviewed the main findings of the studies and addressed their limitations.

\section{STUDIES OVERVIEW}

Our initial search yielded 389 references, 288 of which were initially excluded, based on eligibility criteria, leaving 101 articles. In a subsequent analysis 71 references were excluded after the abstracts were reviewed. Ultimately, 13 
studies were included: 9 on TNS ( 5 clinical trials, $n=41$ subjects and 4 preclinical studies, i.e, studies evaluating the effects of TNS over animal models) and 4 clinical studies ( $\mathrm{n}=84$ subjects) on tVNS.

\section{TRIGEMINAL NERVE STIMULATION}

The initial animal studies of TNS focused on epilepsy. First, experimental models were based on pentylenetetrazole-induced seizure in conscious adult rats. This chemical causes a generalized tonic-clonic seizure with a 4-second period at a frequency of 4 per minute for approximately 2 hours. After the drug was administered, TNS was performed, reducing seizure activity in the thalamus and neocortex. The clinical response of TNS depends on the stimulus frequency and intensity [9]. In humans, TNS is performed through electric stimulation at $120 \mathrm{~Hz}$ with a pulse wave duration of 250 microseconds and cycle of 30 seconds. Electrical stimuli creates an asymmetrical biphasic pulse wave, adjustable from 0 to $100 \mathrm{mAs}$.

In an open-label study ( $\mathrm{n}=07)$, DeGiorgio et al. evaluated the efficacy of TNS in epilepsy. Fifty-seven percent of the sham experienced $\mathrm{a} \geq 50 \%$ reduction in seizures after TNS. This pilot exploratory study indicated that transcutaneous stimulation of the supraorbital and infraorbital divisions of the trigeminal nerve was safe and well tolerated for the 3and 6-month treatment periods ${ }^{10}$. In a 12-month follow-up open-label trial $(n=14)$, the authors reported a satisfactory result of TNS for epilepsy, which effected a mean reduction in seizure frequency of $66 \%$ after 3 months, $66 \%$ at 6 months, and $56 \%$ at 12 months ${ }^{11}$.

Some years later, this group published another open-label exploratory study on external TNS in 14 subjects, focusing on its side effects. Supraorbital and infraorbital TNS was well tolerated, and there were no significant acute or long-term adverse effects on heart rate or systolic or diastolic blood pressure and no major clinical side effects ${ }^{12}$.

There are few publications on the use of TNS for psychiatric disorders. In a recent analysis, TNS was concluded to be a valuable and promising adjuvant to the current therapeutic management of depressive disorders ${ }^{7}$.

In a recent study, Shraeder et al. described 5 patients (60\% female; mean age 49.6 years) with treatment-resistant depression who received TNS over an 8-week follow-up ${ }^{7}$. Subjects had electrodes (Superior Silver 1.25-in. diameter, Tyco) placed on their foreheads to stimulate the V1 branches of the trigeminal nerve bilaterally for approximately 8 hours each night ( 8 weeks; 55 nights). Current was adjusted to maintain comfortable but perceptible levels of stimulation (EMS7500 Stimulator, TENS Products, Inc. Granby, CO, USA). As a result, remission rates of depressive symptoms reached $70 \%$ in the 2-month follow-up.
TNS has been generally well tolerated in research protocol studies ${ }^{13}$. Side effects are infrequent, transient, and mild and include skin irritation, tingling, forehead pressure, and headache. DeGiorgio et al. reported no effects by electrocardiograph with regard to heart rate or systolic or diastolic blood pressure and conclude that it was safe hemodynamically ${ }^{11}$.

\section{TRANSCUTANEOUS VAGUS NERVE STIMULATION (TVNS)}

Stefan and colleagues verified the efficacy of tVNS in resistant epilepsy in 10 patients. In this open-label trial, 5 of 7 patients experienced a decrease in seizure frequency after a 9-month follow-up ${ }^{14}$. The safety of tVNS has been reported in phase I trials ${ }^{15,16,17,18,19}$.

A recent randomized controlled pilot study ${ }^{15}$ showed for the first time an antidepressant effect of a non-invasive auricular electrical nerve stimulation. A total of 37 patients suffering from major depression were included in two randomized sham controlled add-on studies, and the patients were stimulated five times a week on a daily basis for the duration of 2 weeks. The antidepressant effect measured by the beck depression inventory (BDI) was very significant: Patients treated with tVNS gained 12.6 (standard deviation (SD) 6.0) points, compared to 4.4 (SD 9.9) points of the sham-stimulated patients (Tables 1 and 2).

\section{STUDY ANALYSIS}

Our literature review comprised 9 clinical and preclinical studies on TNS and 4 clinical studies on tVNS per the study design. The relative lack of data reflects the recent development of these interventions and the need for consistent interventional studies to determine their clinical value and limitations.

We retrieved 4 preclinical and 5 clinical studies on TNS. All clinical data were based on open-label studies with small samples (total of 44 patients in the clinical studies), which precluded the use of TNS as a tool for clinical practice.

There were 4 clinical studies on tVNS (total of 84 patients - 3 assessed physiological features in healthy volunteers and 1 examined epilepsy patients. One study was a crossover design, and the remaining trials were open-label studies, which also compromised their conclusions and analysis.

\section{ANATOMICAL CONSIDERATIONS}

The basis for using cranial nerve stimulation as an "add-on" therapy for psychatric disorders underscore the 
Table 1. Overview of data extraction and quality assessment - Clinical Studies trigeminal enrve stimulation.

\begin{tabular}{|c|c|c|c|c|c|c|}
\hline Authors & $\begin{array}{l}\text { Study } \\
\text { design }\end{array}$ & Subjects & $\begin{array}{l}\text { Diagnosis / } \\
\text { assessment }\end{array}$ & Intervention & Main Outcome & Biases Sumary \\
\hline $\begin{array}{l}\text { DeGiorgio, } \\
2006\end{array}$ & $\begin{array}{l}\text { Open } \\
\text { Label } \\
\text { Study }\end{array}$ & 7 & $\begin{array}{l}\text { Epilepsy; } \\
\text { Clinical } \\
\text { assessment }\end{array}$ & TNS & $\begin{array}{l}57 \% \text { of the sample experienced } \\
\text { a } \geq 50 \% \text { reduction in seizures } \\
\text { after TNS intervention. }\end{array}$ & $\begin{array}{l}\text { Small sample size, poor demographical } \\
\text { sample description, low impact of } \\
\text { results generalizability. }\end{array}$ \\
\hline Pop, 2011 & $\begin{array}{l}\text { Open } \\
\text { Label } \\
\text { Study }\end{array}$ & 14 & $\begin{array}{l}\text { Epilepsy; } \\
\text { Clinical } \\
\text { assessment }\end{array}$ & TNS & $\begin{array}{l}\text { No signicant acute or long-term } \\
\text { major adverse effects. }\end{array}$ & $\begin{array}{l}\text { Small sample size, poor demographical } \\
\text { sample description, low impact of } \\
\text { results generalizability. }\end{array}$ \\
\hline $\begin{array}{l}\text { DeGiorgio, } \\
2009\end{array}$ & $\begin{array}{l}\text { Open } \\
\text { Label } \\
\text { Study }\end{array}$ & 13 & $\begin{array}{l}\text { Epilepsy; } \\
\text { Clinical } \\
\text { assessment }\end{array}$ & TNS & $\begin{array}{l}\text { Mean seizure frequency } \\
\text { reduction: } 66 \%(3 \mathrm{~m}) \\
56 \%(6 \mathrm{~m}) \text { and } 59 \%(12 \mathrm{~m}) \text {. }\end{array}$ & $\begin{array}{l}\text { Small sample size, poor demographical } \\
\text { sample description, low impact of } \\
\text { results generalizability. }\end{array}$ \\
\hline $\begin{array}{l}\text { Schraeder, } \\
2011\end{array}$ & $\begin{array}{l}\text { Open } \\
\text { Label } \\
\text { Study }\end{array}$ & 5 & $\begin{array}{l}\text { TRD / IDC-10; } \\
\text { HDRS; BDI }\end{array}$ & TNS & $\begin{array}{c}\text { Significant decreases in symptom } \\
\text { severity were observed over } \\
8 \text { weeks. }\end{array}$ & $\begin{array}{l}\text { Small sample size, low impact of } \\
\text { results generalizability. }\end{array}$ \\
\hline $\begin{array}{l}\text { DeGiorgio, } \\
2003\end{array}$ & $\begin{array}{l}\text { Open } \\
\text { Label } \\
\text { Study }\end{array}$ & 2 & $\begin{array}{l}\text { Epilepsy; } \\
\text { Clinical } \\
\text { assessment }\end{array}$ & TNS & $\begin{array}{l}\text { TNS was well tolerated and patients } \\
\text { reported reductions in seizures } \\
\text { during stimulation. }\end{array}$ & $\begin{array}{l}\text { Small sample size, low impact of } \\
\text { results generalizability. }\end{array}$ \\
\hline
\end{tabular}

importance of clearly understanding neuroanatomic pathways related to the stimulated nerve.

The trigeminal nerve is 1 of the 12 pairs of cranial nerves and has motor and sensory function. It originates from a motor nucleus and 3 sensory nuclei that extend throughout most of the length of the brain stem. The vagus nerve comprises motor and sensory fibers. The filaments of this nerve unite and form a flat cord that passes beneath the flocculus to the jugular foramen, through which it leaves the cranium.

The vagus and trigeminal nerves project directly to serotoninergic and noradrenergic neurons in the brain, which generate specific neurotransmitters (serotonin and noradrenaline) that are linked to many neuropsychiatric disorders, such as mood and anxiety disorders. Other vagal and trigeminal neuronal projections are directed toward central brain stem structures, such as the nucleus solitarius, locus coeruleus, and reticular formation, and to other limbic, sensory, cortical, and subcortical areas, such as the locus coeruleus, orbitofrontal cortex, insula, hippocampus, and amygdala. The propagation of electric stimuli through these neuronal projections from peripheral sites to the central nervous system has been proposed to constitute the neurobiological basis of central nervous system (CNS).

\section{THE “BOTTOM-UP”MECHANISM}

In current neuromodulation scenario, clinical results have been working as trully hypothesis driven forces, i.e., empirical observation and data analysis from different studies have been highlighting possible mechanisms related to the neurobiological functioning of neuromodulation

Table 2. Overview of data extraction and quality assessment - Clinical Studies trigeminal vagus nerve stimulation.

\begin{tabular}{|c|c|c|c|c|c|c|}
\hline Authors & $\begin{array}{l}\text { Study } \\
\text { design }\end{array}$ & Subjects & $\begin{array}{l}\text { Diagnosis / } \\
\text { assessment }\end{array}$ & Intervention & Main Outcome & Biases Sumary \\
\hline $\begin{array}{l}\text { Busch, } \\
2012\end{array}$ & Crossover & 48 & $\begin{array}{l}\text { Health volunteers; } \\
\text { study on pain } \\
\text { physiology }\end{array}$ & tVNS & $\begin{array}{l}\text { tVNS was related to an increase } \\
\text { in mechanical and pressure } \\
\text { pain threshold and a reduction } \\
\text { of mechanical pain sensitivity. }\end{array}$ & $\begin{array}{l}\text { Small sample size, poor } \\
\text { demographical sample } \\
\text { description, low impact of } \\
\text { results generalizability. }\end{array}$ \\
\hline $\begin{array}{l}\text { Stefan, } \\
2012\end{array}$ & $\begin{array}{l}\text { Open Label } \\
\text { Study }\end{array}$ & 10 & $\begin{array}{l}\text { Pharmacoresistant } \\
\text { Epilepsy; Clinical } \\
\text { assessment }\end{array}$ & tVNS & $\begin{array}{c}7 \text { patients concluded the trial and } \\
\text { presented an overall reduction } \\
\text { of } 71.4 \% \text { of seizure frequency } \\
\text { after a } 9 \text {-month follow up. }\end{array}$ & $\begin{array}{l}\text { Small sample size, poor } \\
\text { demographical sample } \\
\text { description, low impact of } \\
\text { results generalizability. }\end{array}$ \\
\hline $\begin{array}{l}\text { Dietrich, } \\
2008\end{array}$ & $\begin{array}{l}\text { Open Label } \\
\text { Study }\end{array}$ & 4 & $\begin{array}{l}\text { Health volunteers; } \\
\text { neuroimaging } \\
\text { study on brain } \\
\text { activation patterns }\end{array}$ & tVNS & $\begin{array}{c}\text { A positive } \mathrm{fMRI} \text { BOLD response } \\
\text { was detected during stimulation } \\
\text { in different brain areas. }\end{array}$ & $\begin{array}{l}\text { Small sample size, poor } \\
\text { demographical sample } \\
\text { description, low impact of } \\
\text { results generalizability. }\end{array}$ \\
\hline $\begin{array}{l}\text { Kraus, } \\
2007\end{array}$ & $\begin{array}{l}\text { Open Label } \\
\text { Study }\end{array}$ & 22 & $\begin{array}{l}\text { Health volunteers; } \\
\text { neuroimaging study } \\
\text { on brain activation } \\
\text { patterns }\end{array}$ & tVNS & $\begin{array}{l}\text { fMRI BOLD-signal decreases in } \\
\text { limbic brain areas. Increased } \\
\text { activation was seen in the insula, } \\
\text { precentral gyrus and the thalamus. }\end{array}$ & $\begin{array}{l}\text { Small sample size, low } \\
\text { impact of results } \\
\text { generalizability. }\end{array}$ \\
\hline $\begin{array}{l}\text { Hein, } \\
2013\end{array}$ & $\begin{array}{l}\text { Double- } \\
\text { blinded sham } \\
\text { controled trial }\end{array}$ & 37 & $\begin{array}{c}\text { Patients with } \\
\text { depressive disorder }\end{array}$ & tVNS & $\begin{array}{l}\text { In contrast to sham-treated } \\
\text { patients, electrically stimulated } \\
\text { persons showed a significantly } \\
\text { better outcome in the BDI. }\end{array}$ & $\begin{array}{l}\text { Small sample size, low } \\
\text { impact of results } \\
\text { generalizability. }\end{array}$ \\
\hline
\end{tabular}


strategies. The precise mechanisms by which CNS exerts its effects remain unknown. Empirical evidence has been reported, suggesting that CNS causes long-term neuroplasticity in the brain. Two chief explanations have been hypothesized for the effects of TNS, primarily from preclinical research. First, neuronal firing is suppressed during TNS in rats as soon as nerve stimulation begins ${ }^{20}$. Further, in humans, tVNS and TNS are typically provided on a continuous fixed-duty cycle, and in animal studies, there is a period during which the seizure threshold increases after each "on" cycle terminates $^{8}$. There might also be effects of cranial nerve stimulation that last from tens of seconds to minutes and outlast the period of nerve stimulation. In addition, there appear to be long-term effects of cranial nerve stimulation that tend to decrease in over months to years ${ }^{15,16,17}$.

Electric stimulation provides direct modulatory effects in subcortical sites, i.e, there are changes in cortical excitability. Neuroimaging studies corroborate these effects, showing neuronal activity changes in certain sites of brain, such as the amygdala, insula, precentral gyrus, hippocampus, and thalamus ${ }^{4,5,16,21}$. These neuroanatomical connections have been linked to the "bottom-up" mechanism of modulation by $\mathrm{CNS}^{9}$. According to this hypothesis, the propagation of electric stimuli follows an inverse path from peripheral nerves toward the brain stem and central structures, as discussed.

The centrifuges electric propagation throughout neurons contrasts with the well-known "top-down" mechanism of other modulation strategies, such as electroconvulsive therapy and transcranial magnetic stimulation, in which the stimulus acts first on central brain structures, with propagation later to peripheral sites.

\section{SUMMARY OF CURRENT CLINICAL USE OF TVNS AND TNS}

Both TNS and tVNS are performed by the placement of a bipolar electrode transcutaneously over superficial branches of either trigeminal or vagus nerve, which results in further dissemination of a low-frequency electric pulse from the nerve toward the central nervous system. Electric stimulation of the nerve has direct modulatory effects in subcortical sites.

The use of cranial nerve stimulation in current psychiatric practice is sparse and still limited to a few research protocols. TNS an tVNS are recent interventions that causes minor adverse effects. A relevant feature is their transcutaneous-based stimuli, which stands for a non invasive procedure.

\section{FINAL REMARKS}

TNS and tVNS are techniques that, despite their recent development, have ellected satisfactory outcomes in the past decade, which have engendered further research in many clinical situations. Additional controlled studies are needed to overcome the difficulties of standardizing and disseminating the technique. Long-term clinical outcomes and new applications for these techniques in other neuropsychiatric disorders will be invaluable in clinical practice. TNS and tVNS improve treatment of particular neuropsychiatric disorders such as depression, and their development will allow clinicians to intervene in neuroplasticity and neuromodulation.

\section{References}

1. Krishnamoorthy ES. Treatment of depression in patients with epilepsy: problems, pitfalls, and some solutions. Epilep Behavn 2003;4(Suppl):S46-S54.

2. Howland RH, Shutt LS, Berman SR, Spotts CR, Denko T. The emerging use of technology for the treatment of depression and other neuropsychiatric disorders. Ann Clin Psychiatry 2011;23:48-62.

3. Loo C, Katalinic N, Mitchell PB, Greenberg B. Physical treatments for bipolar disorder: a review of electroconvulsive therapy, stereotactic surgery and other brain stimulation techniques. J Affect Disord 2011;132:1-13.

4. Mohr P, Rodriguez M, Slavovfçkov A, Hanka J. The application of vagus nerve stimulation and deep brain stimulation indepression. Neuropsychobiology 2011;64:170-181.

5. Brunoni AR, Teng CT, Correa C, et al. Neuromodulation approaches for the treatment of major depression: challenges and recommendations from a working group meeting. Arq Neuropsiquiatr 2010;68:433-451.

6. Daban C, Martinez-Aran A, Cruz N, Vieta E. Safety and efficacy of vagus nerve stimulation in treatment-resistant depression. A systematic review. J Aff Disord 2008;110:1-15
Schrader LM, Cook IA, Miller PR, Maremont ER, DeGiorgio CM, Trigeminal nerve stimulation in major depressive disorder: first proof of concept in an open pilot trial. Epilep Behav 2011;22:475-478.

8. Moher D, Liberati A, Tetzlaff J, Altman DG. Preferred reporting items for systemtic reviews and meta-analyses: the PRISMA statement. PLos Med 2009;6:10000097.

9. Fanselow EE, Reid A, Nicolelis AL. Reduction of pentylenetetrazole induced seizure activity in awake rats by seizure-triggered trigeminal nerve stimula- tion. J Neurosci 2000;20:8160-8168.

10. DeGiorgio CM, Shewmon DA, Whitehurst T. Trigeminal nerve stimulation for epilepsy. Neurology 2003;61:421-422.

11. DeGiorgio C, Murray D, Markovic D Whitehurst T. Trigeminal nerve stimulation for epilepsy: long-term feasibility and efficacy. Neurology 2009;72:936-938.

12. Pop J, Murray D, Markivic D, DeGiorgio CM. Acute and long-term safety of external trigeminal nerve stimulation for drug-resistant epilepsy. Epilep Behav 2011;22:574-576.

13. DeGiorgio CM, Shewmon DA, Murray D, Whitehurst T. Pilot study of trigeminal nerve stimulation (TNS) for epilepsy: a proof-of-concept trial. Eplepsia 2006;47:1213-1215. 
14. Stefan H, Kreiselmeyer G, Kerling F, et al. Transcutaneous vagus nerve stimulation (t-VNS) in pharmacoresistant epilepsies: a proof of concept trial. Epilepsia 2012;53:115-118.

15. Kraus T, Hösl K, Kiess O, Schanze A, Kornhuber J, Forster C. BOLD fMRI deactivation of limbic and temporal brain structures and mood enhancing effect by transcutaneous vagus nerve stimulation. J Neural Transm 2007;114:1485-1493.

16. Dietrich S, Smith J, Scherzinger C, et al. A novel transcutaneous vagus nerve stimulation leads to brainstem and cerebral activations measured by functional MRI. Biomed Tech (Berl) 2008;53:104-111.

17. Revesz D, Tjernstrom M, Ben-Menachem E, et al. Effects of vagus nerve stimulation on rat hippo- campal progenitor proliferation. Exp Neurol 2008;214:259-265.
18. Andrade P, Noblesse LH, Temel Y, et al. Neurostimulatory and ablative treatment options in major depressive disorder: a systematic review. Acta Neurochir (Wien) 2010;152:565-577.

19. Busch V, Zeman F, Heckel A, Menne F, Ellrich J, Eichhammer P. The effect of transcutaneous vagus nerve stimulation on pain perception: an experimental study. Brain Stimul 2013;6:202-209.

20. Morris GL 3rd, Mueller WM. Long-term treatment with vagus nerve stimulation in patients with refrac- tory epilepsy. The Vagus Nerve Stimulation Study Group E01-E05. Neurology 1999;53:1731-1735

21. Schlaepfer TE, George MS, Mayberg H. WFSBP Guidelines on brain stimulation treatments in psychiatry. WFSBP task force on brain stimulation. World J Biol Psychiatry 2010;11:2-18. 